\title{
Relação pedagógica em tempo de isolamento: contributo para uma análise reflexiva
}

Pedagogical relationship in isolation time: contribution to a reflexive analysis

Miguel Mata Pereira* - ISPA miguelmatap@me.com

doi: $x x x x x x x x x x x$

\begin{tabular}{|c|c|c|}
\hline Recebido / Received & Aceite / Accepted & Publicado / Published \\
19.07 .2020 & 1.09 .2020 & 1.06 .2021 \\
\hline
\end{tabular}

Como citar este capítulo / How to quote this chapter:

Pereira, M. M. (2021). "Relação pedagógica em tempo de isolamento: contributo para uma análise reflexiva". In Reis, B., Um mundo de incertezas; as leituras possíveis de um tempo pandémico (pp. 169-184). Lisboa: NIP-C@M \& UAL, disponível em $\underline{x x x x x x x x x}$. DOI xxxxxxx.

* Centro de Investigação em Educação do ISPA- Instituto Superior de Ciências Psicológicas, Sociais e da Vida

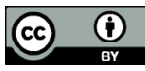


"A libido sciendi, a sede do conhecimento, a necessidade profunda de compreender estão inscritas no que de melhor têm os homens e as mulheres. Tal como a vocação do professor. Não há ofício mais privilegiado. Despertar noutro ser humano poderes e sonhos até dos seus; induzir nos outros um amor por aquilo que amamos; fazer do seu presente interior o seu futuro: eis uma tripla aventura como nenhuma outra"

George Steiner (2005: 148).

\section{Preâmbulo}

Circunscrevamos a "tribo" de referência: psicologia cultural ${ }^{1}$. Objetivemos a problemática: impacto do isolamento resultante das medidas de enfrentamento da pandemia COVID-19 sobre a relação pedagógica, a sua importância no desenvolvimento e aprendizagem dos alunos. Enquadremos a problemática: em 2 de março de 2020 foi confirmado o primeiro caso de infeção pelo novo Coronavírus em Portugal. Apenas 10 dias depois, em 12 de março, e em função da evolução da situação epidemiológica então observada, o governo português decidiu decretar o encerramento das escolas e estabelecimentos de ensino. Volvidos mais 10 dias, em 22 de março, foi decretado o Estado de Emergência em Portugal, como medida restritiva extrema de combate à pandemia, que vigorou até dia 2 de maio. Não obstante, o ano letivo manteve-se em regime de ensino à distância até ao seu término, em 26 de junho. 
escolas, todos os seus agentes e atores tiveram para preparar uma súbita e inesperada transição do ensino presencial para o ensino à distância, por forma a dar continuidade aos percursos escolares iniciados. Em poucas semanas e de forma abrupta surgiram listas de aplicações e plataformas educativas com o intuito de ajudar os pais, professores, estabelecimentos, e responsáveis pedagógicos a facilitar a aprendizagem dos alunos. A proporcionar interações e serviços sociais durante o encerramento das escolas e o consequente isolamento a que foram votados todos os intervenientes dos contextos educacionais e escolares. Assistimos assim, a uma alteração radical do quotidiano escolar, uma passagem da sala de aula como espaço físico privilegiado para o estabelecimento de relações pedagógicas, de interações dialógicas e de socialização, para um espaço virtual, alojado numa plataforma digital a que todos deveriam aceder para poder dar prosseguimento aos processos de aprendizagem-ensino.

O presente ensaio pretende contribuir para uma reflexão sobre esta transição da escola presencial para a escola virtual, debruçando-se em particular sobre o impacto desta mudança na relação entre professores, alunos e aprendizagens, suas potenciais consequências e eventuais ilações futuras.

\section{Da relação pedagógica}

De acordo com Steiner (2004: 12), os seres humanos são zoon phonanta, animais dotados de linguagem. A comunicação verbal e não-verbal - constitui a base da relação pedagógica. É desta interação dialógica e conversacional, que emerge a von- 
tade de querer conhecer o outro e com ele aprender, influenciando comportamentos, atitudes, pensamento e discernimento:

\begin{abstract}
“A interação é uma reação recíproca verbal ou não-verbal, temporária ou repetida segundo uma certa frequência, através da qual o comportamento de um dos parceiros tem influência sobre o comportamento do outro. Ela tem lugar tanto num sistema dialéctico - a acção do docente afeta o aluno e vice-versa - como no sistema mais amplo da turma, colocando-se o indivíduo em relação com o grupo e com subgrupos" (Postic, 2007: 146).
\end{abstract}

O conhecimento mútuo que professor e aluno vão entabulando, aprofunda a relação e a afetividade, possibilitando que ambos possam ir tomando consciência da presença ativa e desejada do outro, com base nos indicadores subtis omnipresentes nas interações comunicativas:

"Não esqueçamos que se deve ter em conta o aspecto verbal da comunicação, que compreende a informação e a maneira de apresentar a informação e também os aspectos nãoverbais da comunicação, porque certas mímicas, certos sinais gestuais são indicadores de um estado, os índices de uma intencionalidade. Estas formas não-verbais de expressão no docente, o sorriso, o olhar, o franzir o sobrolho, o trejeito, os movimentos da cabeça, que aprovam ou desaprovam, o gesto das mãos e dos dedos que designam os alunos e os convidam a exprimir-se, as posturas corporais que indicam surpresa, a expectativa, o interesse, a decepção, etc., são 
espontaneamente descodificados pelos alunos em sinais positivos, negativos ou neutros" (Postic, 2007: 138).

Halliday na sua teoria da aprendizagem baseada na linguagem argumenta que toda a aprendizagem está saturada de comunicação e linguagem:

“Quando as crianças aprendem a linguagem, elas não estão simplesmente engajadas num tipo de aprendizagem entre muitos; em vez disso, elas aprendem os fundamentos da própria aprendizagem. A característica distintiva da aprendizagem humana é que ela é um processo de construção de significado - um processo semiótico; e a forma prototípica da semiótica humana é a linguagem. Consequentemente, a ontogênese da linguagem é ao mesmo tempo a ontogênese da aprendizagem" (1993: 93).

Uma parte importante do desenvolvimento intelectual e do ato de aprendizagem é promovido pelas interações conversacionais, baseando-se essencialmente num processo de construção de significado com os outros, transversal a todos os níveis de educação e ensino. O pensamento e a aprendizagem têm por base a relação afetiva e a linguagem (Santos, 2007). Em particular, as relações entre professores e alunos reenviam para interações de natureza íntima, de partilha e descoberta mútuas. Por osmose, como nos fala Steiner, "o Mestre aprende com o discípulo ao mesmo tempo que o instrui. A intensidade do diálogo gera amizade no sentido mais elevado do termo" (2005: 12). 
Deste encontro nasce a relação pedagógica, fundada no afeto e respeito mútuo, na vontade de descobrir com autenticidade o outro, de promover e provocar a sua emancipação, a sua liberdade e livre arbítrio. Juntos, professor e aluno percorrem a pista de corrida - o curriculum escolar e disciplinar. A velocidade, a intensidade, o treino, a integração dos conhecimentos, a implicação e o processo de aprendizagem-ensino vão sendo ajustados, calibrados, reformulados. A intersubjetividade consubstancia esta aproximação. A empatia operacionaliza esta possibilidade.

O compromisso entre professor e aluno cria as condições para a emergência de um ambiente social de sala de aula positivo, baseado no estabelecimento de um clima relacional, afetivo e social sustentado na confiança e aceitação mútua, determinantes da qualidade educativa uma vez que o afeto, as motivações e a relação interpessoal são compostos nucleares dos processos educativos e da relação pedagógica.

A promoção de uma atmosfera positiva na sala de aula envolve padrões elevados e frequentes de comunicação entre alunos, e entre alunos e professores; os professores evidenciam atitudes e expetativas positivas em relação aos alunos, e demonstram interesse por eles enquanto pessoas e não, exclusivamente, enquanto alunos. Através da relação estabelecida e consolidada com os alunos, o professor vai reforçando a sua capacidade para entender o que a experiência de sala de aula significa para cada aluno, acolhendo uma diversidade de opiniões, vontades e desejos. 
A gestão de sala de aula implica o professor num planeamento e reflexão crítica relativamente a aspetos do processo de ensino e da didática que englobam a gestão do tempo, do espaço, dos materiais, das atividadese, com grande importância, das relações. A operacionalização destes vetores mobiliza competências - um saber-fazer em ação - que vão sendo apuradas e experimentadas em contexto: varrer a sala com o olhar, lidar com mais do que uma situação em simultâneo, adaptação do ritmo da aula, adequação ao nível de entendimento e capacidades dos alunos. Este eixo metodológico do processo de aprendizagemensino, associado ao eixo relacional, consubstancia a relação pedagógica e o jogo de expetativas e profecias, entre professor e aluno, aventando os objetivos major do sucesso educativo e da igualdade de oportunidades para participar.

Não obstante, o ensino secular que a escola tem reproduzido alimenta-se da imitação, do desvelar e memorizar de matérias e conhecimentos transmitidos de forma unidirecional, com pouco ou nenhum questionamento, com lugar diminuto para a exploração da curiosidade, do espírito crítico, da descoberta. O professor como autoridade didática dita o exemplo a seguir, demonstrando o seu domínio sobre as matérias escolares, com pleno poder atribuído pela escola e pelos alunos. Mas estarão os alunos sempre disponíveis para acolher este exemplo? Quererão segui-lo? Identificar-se-ão com ele? Perguntas desta tonalidade constituem o âmago do pensamento pedagógico, permanecendo em aberto, e as respostas possíveis não servem generalizações. $O$ ato de ensinar - como o de aprender - é um 
processo dialético, “(...) ensinar com seriedade é lidar no que existe de mais vital num ser humano. É procurar acesso ao âmago da integridade de uma criança ou de um adulto" (Steiner, 2005: 25).

A persuasão constitui-se como o pulso do ensino: o professor requer a atenção do aluno e explicita o seu ponto de vista sobre uma matéria. Idealmente, o aluno porá em questão o que está a aprender, para que possa apreender, isto é, transformar e integrar o conhecimento de acordo com o sentido que atribui e a significação que retira. Esta discordância, este desencontro de dois intelectos, incentiva o desenvolvimento, força a ir para além das evidências, reequilibra o posicionamento de quem instrui e de quem é instruído. A redundância da comunicação numa relação pedagógica serve o propósito de afinar o ato perlocutório.

A relação pedagógica assenta a sua centralidade no processo educativo através da intersubjetividade, da intencionalidade e da interação dialógica, “(...) é pela mediação dos outros, pela mediação do adulto que a criança se incumbe de atividades. Absolutamente tudo no comportamento da criança está incorporado e enraizado em relações sociais. Desse modo, as relações da criança com a realidade são, desde o início, relações sociais (...)" (Ivic, 1989: 429).

Outro dos pilares da relação pedagógica é o contrato didático, que enuncia a interligação entre o professor, o aluno e o saber. 
Este contrato pressupõe uma parte explícita - a tarefa que o professor propõe ao aluno realizar - e uma parte implícita correspondente ao trabalho de descoberta do aluno para poder corresponder à tarefa solicitada pelo professor. Se a parte implícita é incomportável para o aluno, se situa fora da sua competência, incompreensível, o professor deverá implicar-se num esforço de adaptação que mobiliza uma reconstrução do saber e da comunicação em função das capacidades cognitivas do aluno, dos seus conhecimentos anteriores, das estruturas e lógicas de pensamento já adquiridas.

\section{Relação pedagógica e isolamento: análise crítica}

A relação pedagógica é um palco de afetividade. Para alguns alunos, esta razão é a principal razão que os liga à escola e às aprendizagens. Professor como figura de referência, base segura para despoletar outros relacionamentos, aqueles que com o crescimento vão ganhando cada vez mais relevância: o grupo de pares que anuncia as amizades e a intimidade. No dizer de Postic "a relação educativa não se situa apenas ao nível da comunicação interpessoal, desenvolve-se ao nível dos afectos, dos fantasmas e por isso no registo do inconsciente" (2007: 15).

O isolamento, o confinamento - expressão que cunhou o tempo passado em casa, longe da escola, da comunidade, dos amigos trouxe dificuldades acrescidas para os alunos que encontram na escola, substancialmente, um contexto de socialização, mais do que um espaço de aprendizagens formais. Poderão as relações 
virtuais - pedagógicas ou doutro nível - remediar a ausência de relações presenciais? As palavras são aqui escolhidas com parcimónia: remediar, não substituir, pois que uma e outra não parecem ser intermutáveis.

A radicalidade do corte vivenciado por alunos, professores e famílias, não terá permitido um enquadramento suficiente para acautelar que a transição presencial/virtual fosse apropriada pelos alunos mais dependentes da relação com os seus professores. A passagem do quotidiano escolar para os ecrãs, onde a relação pedagógica se projetou, espaço distanciado onde se instalou e passou a existir, significou para muitos alunos uma segregação, um afastamento daquilo que de mais importante a escola pode oferecer-lhes.

A escola - espaço físico de encontro, de aprendizagens e de desenvolvimento - experienciou por breves meses um vislumbre distópico do que poderá um dia vir a tornar-se. As plataformas digitais, que ensaiaram substituir as salas de aula, mostraram as suas fragilidades no que respeita aos aspetos da socialização, da interação, da convivialidade, da cooperação e da comunicação dialógica.

Compreende-se que perante a incerteza, a inexperiência, a necessidade de continuar - essa força motriz da humanidade o ensino virtual ou à distância tenha avançado como resposta. Caber-nos-á a todos - cidadãos da polis - determinar, ou pelo menos influenciar, que tipo de escola queremos para os nossos 
filhos e subsequentes gerações. O longo caminho trilhado pela instituição escolar - do seu elitismo inicial à massificação e à democratização - tem mostrado como alguns dos alicerces que a constituem e a tornam um dispositivo de replicação da lógica dominante permanecem, independentemente da natureza do contato e das relações entre professores e alunos.

Conquistas fundamentais da ciência pedagógica, fruto de aturada investigação, denotaram a sua fragilidade quando pensaríamos que tal já não poderia acontecer: a diferenciação dos percursos de aprendizagem dos alunos, a adequação de metodologias de ensino, das didáticas aos estilos e perfis de competências dos alunos, os métodos ativos e a exploração, a cooperação em detrimento da competição, a auto-regulação das aprendizagens e dos comportamentos, entre tantos outros avanços, parecem ter sido ameaçados, em muitos casos substituídos, pela observância caduca do modo de ensino simultâneo: "ensinar a todos, como se fossem um só".

Os princípios subjacentes a este modo de ensinar, preconizados por La Salle no longínquo ano de 1783, teimam em reaparecer - se é que não estiveram sempre presentes - quando surge o medo do desconhecido ou o temor do retrocesso. Voltamos assim, aquele lugar que conhecemos - ainda que não tenhamos necessariamente gostado - que os nossos antepassados conheceram e que perpetuou a escola dos primórdios. Este revisionismo esbarra na utopia do progresso tecnológico como panaceia para todos os problemas societais. Pode a escola do 
século XXI e do futuro que se seguirá, organizar-se e fundar-se sobre alicerces da escola de antanho? Aparentemente, pode. As novas salas de aula virtuais, os novos espaços de aprendizagem e de convívio à distância, acentuam, em muitos casos, o ensinar todos como se fossem um só. O paradoxo é desnudado sem dificuldade. Nos sistemas mais avançados, nas plataformas com mais capacidade multitarefas, nas tecnologias virtuais de ponta, encontramos o anacronismo de uma escola onde os melhores aprendem porque são capazes de se adaptar e seguir a cultura dominante, e os outros, mesmo equipados de todos os dispositivos - num esforço meritório colossal de governos - se atrasam, se desleixam, soçobram.

As aulas virtuais partem muitas vezes do princípio - esse sim nem sempre real - que professores e alunos assumirão o contrato pedagógico encetado no início de cada ano. Assim, numa tentativa de transposição intrépida de uma normalidade que não pode ser assumida, horários, conteúdos curriculares, exercícios, lições, são transpostas da escola presencial para a escola virtual.

Esperamos que professores e alunos se encontrem, nos mesmos dias da semana, nos mesmos horários, com a mesma vontade e motivação, num espaço virtual, a fazer-de-conta que é escola. Deste simulacro, pois para muitos alunos a significação desta aparente continuidade não é nada evidente, deverão surgir as apropriações das matérias escolares, o decurso regular das aprendizagens, as avaliações e classificações dos alunos 
e professores. A tirania do produto escolar impera nestas circunstâncias. $O$ encontro promovido pelos ecrãs autoriza uma demissão quase total da relação pedagógica e do processo de aprendizagem-ensino. Os alunos podem optar por não frequentar as aulas virtuais alegando problemas com os dispositivos ou com as necessárias ligações virtuais. De resto, em muitas circunstâncias estes problemas são reais, dada a sobrecarga de acessos em simultâneo. Os alunos podem optar por ter a câmara de vídeo desligada, decidindo não se mostrar, não se dar a ver, mas vendo o professor e os demais colegas que escolherem manter a sua câmara ligada. A monitorização e controlo do espaço da "sala de reuniões" ou da "sala de aula virtual" por parte do professor fica irremediavelmente comprometida: estarão os alunos que não são visíveis a seguir o que está a ser trabalhado? Estarão atentos? Estarão a compreender o que está a ser comunicado? Estas respostas ficam por descobrir. O que se passará do outro lado do espelho?

A atenção dos alunos - já de si escassa e dispersa - desfocase com facilidade na ausência dos indicadores não-verbais, dificilmente descortináveis na tela do computador ou no ecrã do telemóvel, cujas funções majestáticas incidem precisamente no sustentar da comunicação verbal, na demonstração de atitudes interpessoais, na transmissão de emoções e sentimentos, na distribuição dos tempos de elocução, e em circunstâncias de encontro e intimidade, que só a proximidade e a presença acarretam como consequência, a própria substituição do discurso oral - aquele olhar que dispensa as palavras. 
No entanto, como sempre acontece em pedagogia, a vontade de continuar em contato, a disponibilidade para estar-com-ooutro, e a adaptabilidade de alunos e professores permitiu a manutenção desse encontro vital, centro da relação entre os alunos e a escola. Mesmo que só através dos ecrãs, ou apenas por intermédio do áudio, imagens e vozes familiares permitiram sonegar a ausência do contato, colocando os afetos num lume brando, alimentando a esperança de no futuro esse lume se tornará num fogo transformador e presencial.

\section{Considerações finais}

É ainda cedo para perceber o impacto que a passagem de uma escola presencial para uma escola virtual provocou nos alunos que se viram envolvidos nesta transposição. A resposta implementada foi necessária, considerando o contexto vivenciado e todas as alterações preconizadas para suster e tentar impedir o contágio pandémico. A experiência avançou porque não foi possível, em tempo útil, encontrar alternativas. Assim, e apesar de todos os sobressaltos e incertezas, os alunos e professores, puderam ir avançando, dando a continuidade possível às relações pedagógicas e às aprendizagens escolares, adaptando-se a uma realidade para a qual não estávamos preparados.

Um dos corolários da experiência do ensino virtual tem sido o entendimento que esta modalidade acentua as desigualdades, não apenas no que respeita às condições de acesso ao ensino 
virtual (computador, internet), mas do lado da participação autêntica, da cooperação, da atribuição e ancoragem de significado às aprendizagens e aos ensinamentos que vão sendo transmitidos.

Por mais distendidas e diversificadas que sejam as metodologias do ensino à distância, a relação pedagógica esmorecerá pela dificuldade extrema de diferenciar ou individualizar processos de aprendizagem. Se quisermos aprofundar, constatamos que a participação ativa dos alunos é diminuta, propagando o modo de ensino simultâneo, ensinando a todos da mesma maneira. A organização social das aprendizagens, os circuitos de comunicação, as mostras de produções, o conselho de turma, as aprendizagens cooperativas, correm o risco de perder significação e autenticidade, passando para a dimensão do simulacro e da teatralização. Os alunos dependem do contexto escolar para dar seguimento ao seu desenvolvimento integral, socialização e participação plena enquanto cidadãos. Desmaterializar a escola e o seu espaço vital pode significar a perda de um sentido profundo de encontro, de igualdade democrática, de inter-relação. 0 profundo ressoar do encontro entre aluno e professor pode vir a tornar-se num eco distante.

Por agora, a experiência de uma escola virtual ficou em suspensão. $O$ tempo de reflexão a propósito das vantagens e desvantagens desta modalidade é curto. Interpela-nos Steiner:

"A relação entre Mestres e discípulos é falível, marcada quase inevitavelmente pela inveja, pela vaidade, pela mentira e pela 
traição. Mas as suas esperanças eternamente renovadas, a maravilha imperfeita da coisa, apontam para a digitas da pessoa humana, para um regresso ao que de melhor existe em nós. Nenhum meio mecânico, por mais expedito que seja, nenhum materialismo, ainda que triunfante, poderá erradicar esse alvorecer interior que experimentamos sempre que compreendemos um Mestre. Essa alegria não torna a morte mais fácil. Mas alimenta a nossa raiva contra o desperdício que ela representa. Não temos tempo para outra lição?" (2005: 149).

\section{Bibliografia}

Halliday, M. A. K. (1993). Towards a language-based theory of learning. Linguistics and Education, 5, pp. 93-116.

Ivic, I. (1989). Profiles of Educators: Lev S. Vygotsky (1896-1934). Prospects XIX(3), pp. 427-436.

Postic, M. (2007). A relação pedagógica. Lisboa: Padrões Culturais Editora.

Santos, J. (2007). A Casa da Praia: O psicanalista na escola. Lisboa: Livros Horizonte.

Steiner, G. (2004). Presenças reais. Lisboa: Presença.

Steiner, G. (2005). As lições dos Mestres. Lisboa: Gradiva. 